\title{
VOLTAGE AND FREQUENCY RESPONSE OF SMALL HYDRO POWER PLANT IN GRID CONNECTED AND ISLANDED MODE
}

\author{
Duncan Kaniaru Maina, Mohammad Javad Sanjari \\ Department of Electrical and Computer Engineering \\ University of Auckland \\ Auckland, New Zealand
}

\author{
Nirmal-Kumar C. Nair \\ Department of Electrical and Computer Engineering \\ University of Auckland \\ Auckland, New Zealand
}

\begin{abstract}
Hydro-based power is gaining more interests as the penetration level of small-scale hydro power plants are being increased to the medium voltage network. This paper investigates the performance of a single unit small hydropower plant in both grid-connected and islanded operation. The overexcitation and volt/hertz excitation limiters have been included in the study to compare their responses in both modes of operation. The plant is evaluated under different loading scenarios considering both resistive and inductive loads. A PI tertiary control for speed reference setting in islanded operation is introduced in the governor to enable regaining of $50 \mathrm{~Hz}$ frequency after load changes. The results obtained from the simulation study show the importance and difference of analysing different loading scenarios both in grid-connected and island modes. Also, the inclusion of PI control in governor aids in returning the frequency to its nominal value.
\end{abstract}

Index Terms - Excitation Limiters, Loading Scenarios, PI Tertiary Control, Small Hydro Power Plant, Turbine-Governor.

\section{INTRODUCTION}

Increasing shift towards a renewable generation portfolio facilitated by improved DG technologies, reduced costs, economic and political incentives has facilitated the growth of hydro, wind, solar, geothermal and biomass-based energy. In terms of hydro power plants, growth is predicted to be in the scales of small, mini, micro and pico ones. Their capacity varies according to different jurisdictions with the most common definition ranges being: Small-hydro (1 - $50 \mathrm{MW})$, Mini-hydro (100 KW - $1 \mathrm{MW}$ ), Micro-hydro (5 KW - 100 $\mathrm{KW}$ ) and Pico-hydro (less than $5 \mathrm{KW}$ ). In this paper, focus is on a small hydro power plant (SHPP) connected at the medium voltage/sub-transmission network. Analysis of large-scale hydro power plants have been provided extensively in the literature, but the performance of small hydro plants remains scanty. References [1-5] have provided a review of small hydro-power plants in terms of modelling, control, economic analysis and the different technologies used.

With the recent increase in natural disasters, the possibility of islanding the distribution MV's network is being considered as an option. Thus, analysis of the SHPP should be done for grid-connected and island mode. Accurate representation of the plant with its turbine-governor system, excitation system limiters is significant. Load should also be modeled not only as resistive but inductive as well. Operation of SHPPs in islanded operation is reviewed in [6]. General distributed generation islanding techniques are first discussed after which a review of small hydro control in terms of speed/active power control and voltage/reactive power control during islanded mode is provided. Performance of the turbine governor system in an isolated SHPP is discussed in [7]. [8] discusses protection performance in a weak distribution network consisting of four synchronous generators and three asynchronous generators. Depending on the generator operation mode which can either be PV (constant active power and voltage), PQ (constant active and reactive power), $\mathrm{PC}$ (constant active power and constant power factor) or Mload (speed-torque characteristics of asynchronous generators), the generators react differently and can either ride through the fault or trip. Investigation into the Low Voltage Ride Through (LVRT) of SHPP is provided in [9] with no mention of excitation limiters modelling in their work. Experience in development of distribution islanding guidelines is discussed in [10] after which a case study of islanding testing of 2, 3.6 MVA run off river small power plants is provided. Change in protection and operational mode settings is required to enable successful islanded operation.

The research works mentioned in the previous paragraph consider the use of general SHPP model, whether gridconnected or island mode, for analysis without including the excitation limiters. This paper provides a comparison of the performance of single unit SHPP in both grid-connected and islanded mode with two of the common excitation limiters present. A PI tertiary control is also introduced to the governor system to return the frequency to nominal value in Island mode. The remainder of the paper is organized as follows: In section II, the test system is described with modeling focusing on the generator and associated controls. Simulation results and subsequent discussions on performance evaluation are presented in section III and section IV respectively. Section V concludes the paper and also provides a glimpse of what should be done in future works.

\section{TEST SYSTEM DESCRIPTION}

A simple system as shown in Fig. 1 is chosen for this study. It consists of a single unit small hydro power plant of $10 \mathrm{MW}$ that generates power at $11 \mathrm{KV}$ with is then stepped up to 33 $\mathrm{KV}$ by the generator step-up transformer. The grid is located $60 \mathrm{KM}$ from the SHPP and is represented by a source with a short circuit capacity of 400 MVA. The load is located 
midpoint between the grid and the SHPP. Data parameters used for the SHPP was obtained from [11] and reproduced in the appendix. Modeling of the system components are further described in the following sections.



Figure 1. Test System

\section{A. Synchronous Generator}

Synchronous generators have long been the core of the power system. Different models for different studies have been described in [12-14]. The sub-transient model described in [14] consisting of stator, field and damper windings is used in this study.

\section{B. Turbine-Governor}

The hydraulic turbine is used to convert kinetic energy from flowing water to a rotating mechanical energy. Different types of turbines have been described in [15-18]. They can be classified as either linear or non-linear with the linear model preferred for steady-state studies while the non-linear model is preferred for dynamic and transient studies. Since our focus is on determining the accurate dynamic response of the hydrogenerator then non-linear model as shown in Fig.2 is chosen for this study.

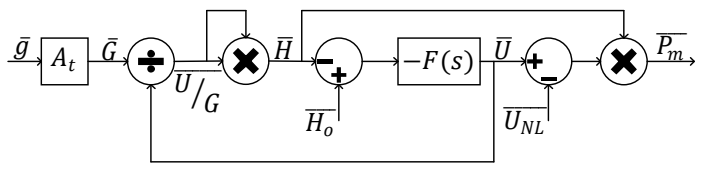

Figure 2. Non-Linear Turbine Model

The choice of the function $\mathrm{F}(\mathrm{s})$ represents the relationship between the turbine velocity and the turbine head. It can take various forms from a simplified function to a function incorporating the elastic water column. The simplified form is assumed in this study and is represented by (1).

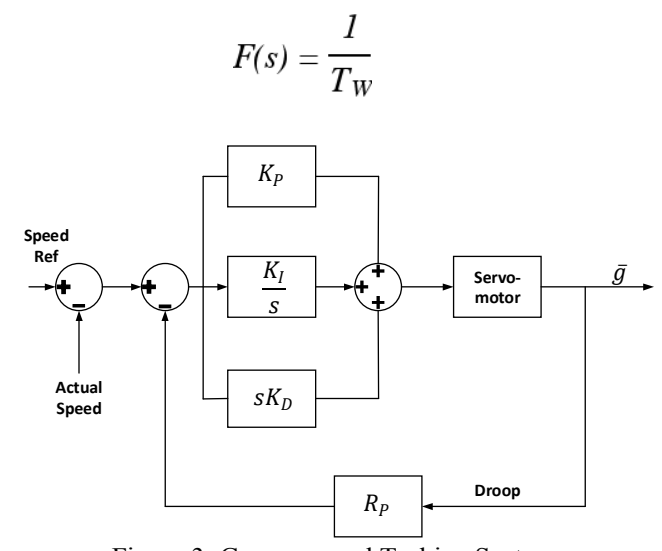

Figure 3. Governor and Turbine System
The hydraulic governor is used to regulate the positioning of the gate and the speed of the turbine, which, in turn, regulates the frequency/active power depending on the set operation mode. There are two common operating modes: droop and Isochronous. In droop control, the generator is set to provide constant power independent of the size of the nearby load. This is commonly used in the rid-connected mode as the grid sets the frequency. Isochronous mode, on the other hand, allows balancing between the vicinity loads and power being produced with the aim of maintaining a constant frequency set point. Electrical hydraulic governors (that replaced mechanical governors) realized by a PID controller as shown in Fig. 3 is used in this study.

\section{Excitation System}

The excitation system is used to provide the rotor windings with the necessary field current required to provide either constant voltage or reactive power. There exist different types of excitation systems: DC, AC and Static Excitation. Comparison of three types of excitation systems is provided in [19]. Static excitation is used in this work as they are the most recently used with the most significant advantage of being fast de-excitation. Their main limitation is that they derive their source of power from the generator terminals thus auxiliary power should be available when starting the power plant with no grid available. Standardised models of excitation systems and limiters are provided in [20]. STA2 which is in MATLAB/SIMULINK library has been used in this study. For proper performance study of a SHPP, it is necessary to incorporate the different excitation limiters which are governed based on each generator's capability curve: Overexcitation limiter (OEL), Voltage/Frequency limiter $(\mathrm{V} / \mathrm{Hz})$, Underexcitation limiter (UEL) and Stator Current Limiter (SCL). The first two are modeled and used in this study.

\section{1) OverExcitation Limiter}

The OEL is used to limit the amount of field current which can damage the field winding. Its operation is governed by the rotor winding thermal capability, that governs the setting of the OEL. Basically, the OEL is a timer allowing high field current to persist for a specified period before limiting it to the rated field current. Depending on how it is integrated with the AVR, there exists two categories [21]: Summed-type OEL in which the OEL output is added to the reference points of the AVR and Takeover OEL in which the output of the OEL bypasses the output of the AVR. Summed type OEL similar to [22], shown in Fig.4 is used in this study. OEL parameters can be found in the appendix.

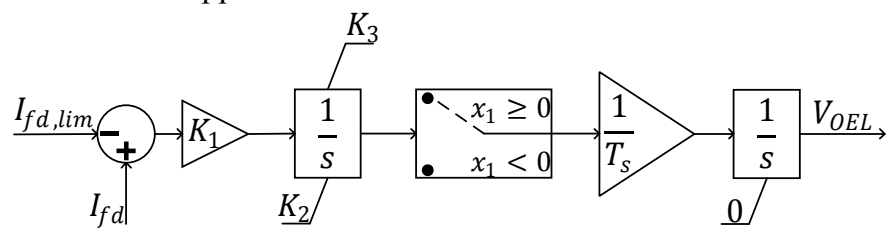

Figure 4. Over-Excitation Limiter 


\section{2) Volts/Hertz Limiter}

Generator over-fluxing may result in excessive eddy currents leading to excessive localized heating either at the stator or rotor cores. Detection of this can be through sensing the voltage/frequency ratio, as shown in (2), that is directly proportional to the flux density level of the machine.

$$
B \alpha \frac{V}{f}
$$

From the equation above, it is observed that over-fluxing can be as a result of high voltage or low frequency. To prevent this issue, the $\mathrm{V} / \mathrm{Hz}$ limiter is incorporated in contributing to the voltage setpoint and setting it according to the frequency levels. As an example [23]: At $50 \mathrm{~Hz}$, the allowable maximum generator voltage is $1.1 \mathrm{pu}$; At $48 \mathrm{~Hz}$, the allowable maximum generator voltage is $1.045 \mathrm{pu}$. Implementation of a V/Hz limiter can be achieved as shown in Fig. $5[11,24]$. The ratio of voltage to frequency is first sensed and compared with the set ratio and if positive then the integrator acts to produce a negative signal that reduces the voltage setpoint until the V/F ratio is below the set ratio. If the difference becomes negative, then the integrator is reset, and no error signal is generated for the voltage setpoint.

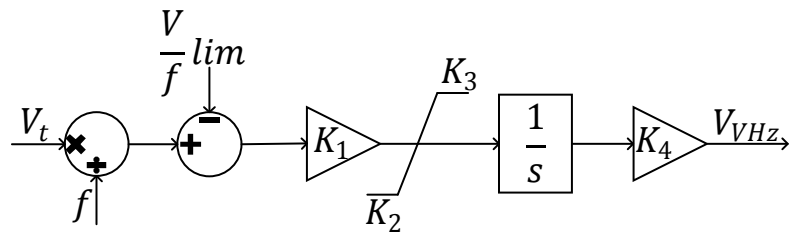

Figure 5. Volt/Hertz Limiter

\section{SIMULATION SCENARIOS}

Different loading scenarios have been created to evaluate the performance of the SHPP.

- Grid-Connected Mode:

- Active Load Steps (MW): 10, 5, 2.5, 0.5.

- Reactive load Steps (MVAr): 10, 5, 2.5, 0.5 .

- Islanded Mode:

- Active Load Steps (MW): 1.5, 1, 0.5, 0.25 .

- Reactive Load Steps (MVAr): 1.5, 1, 0.5, 0.25

It is important to note that the simulation starting load is essential for ensuring initialization stability. The minimum starting load in grid-connected mode and island mode is 0.7 MW and $0.3 \mathrm{MW}$ respectively. The governor control mode in grid-connected and island mode is constant power and constant frequency respectively.

\section{A. Active Load Steps}

The response of the SHPP on different active load steps in grid-connected and island mode is shown in Fig. 6 and Fig. 7 respectively.
1) Grid-Connected Mode
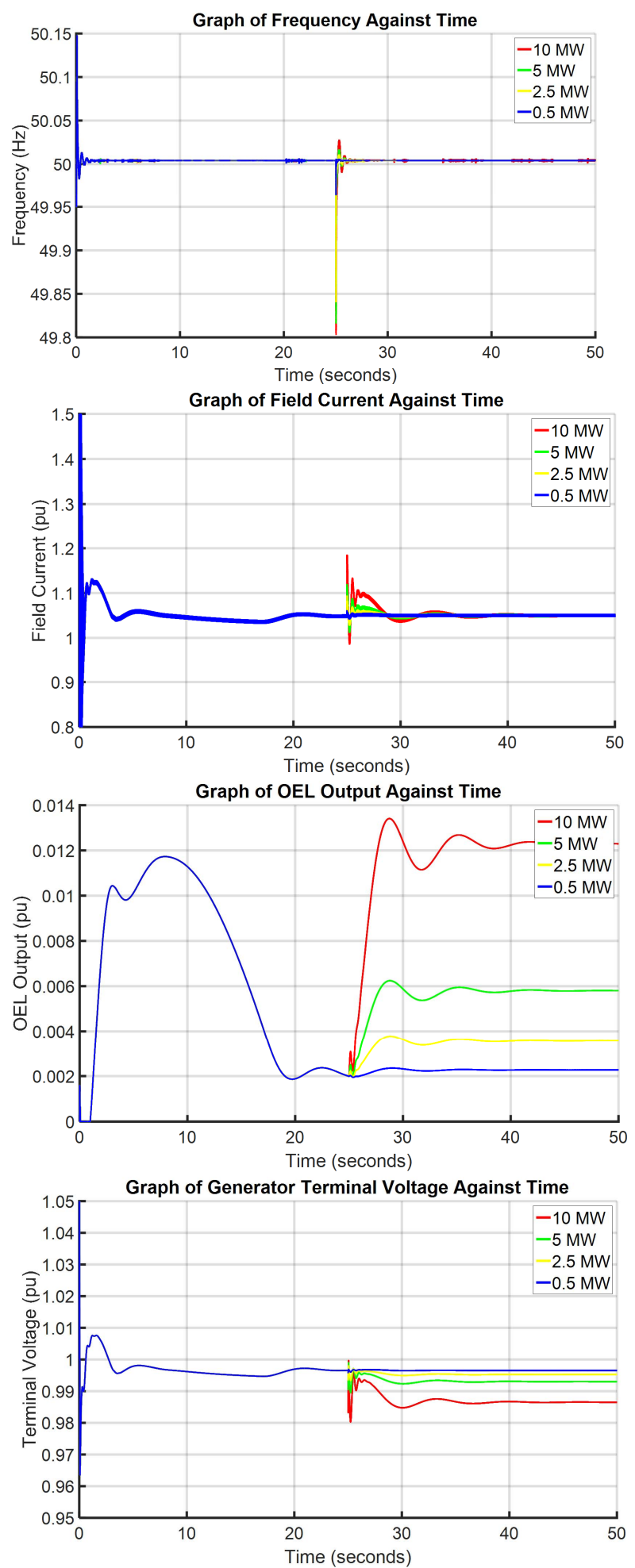

Figure 6. Response in grid-connected mode on different active load steps 
2) Islanded Mode
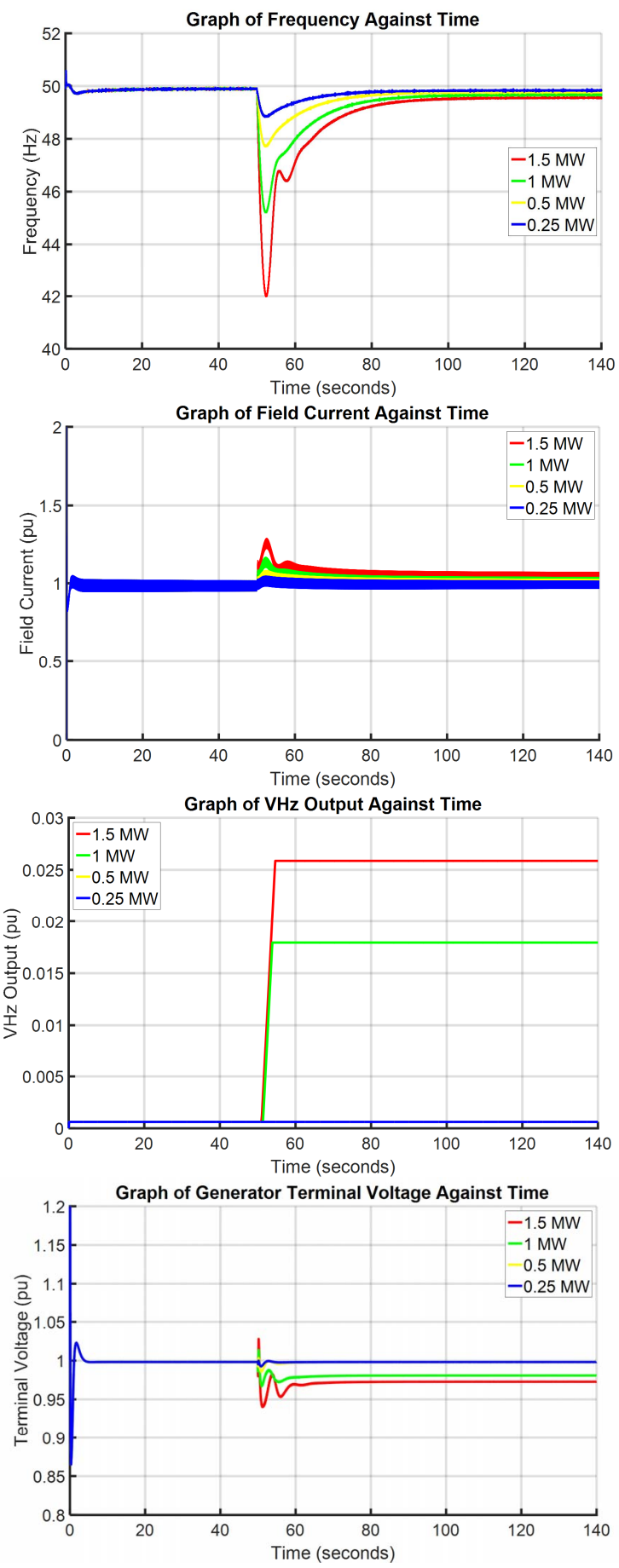

Figure 7. Response in Island mode on different active load steps

\section{B. Reactive Load Steps}

The response of the SHPP on different reactive load steps in grid-connected and island mode is shown in Fig. 7 and Fig. 8 respectively.

1) Grid-Connected Mode
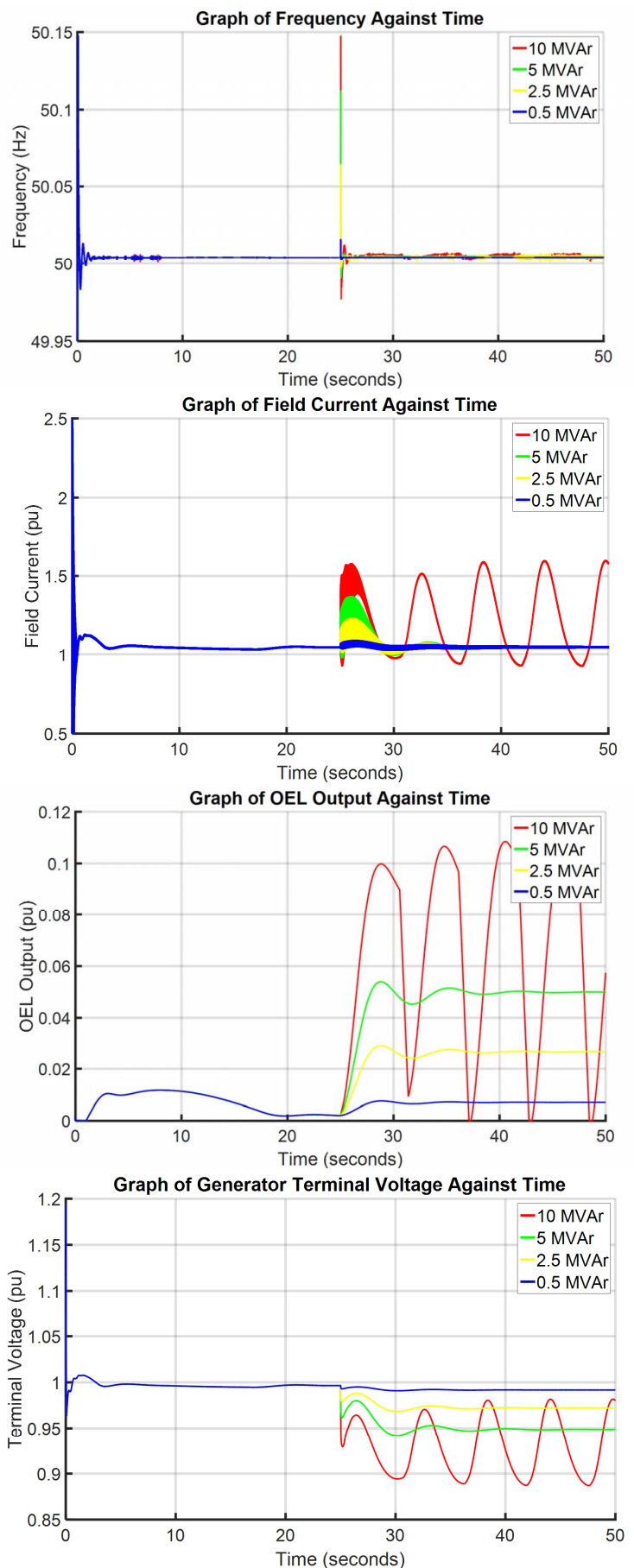

Figure 8. Response in grid-connected mode on different reactive load steps 


\section{2) Islanded Mode}
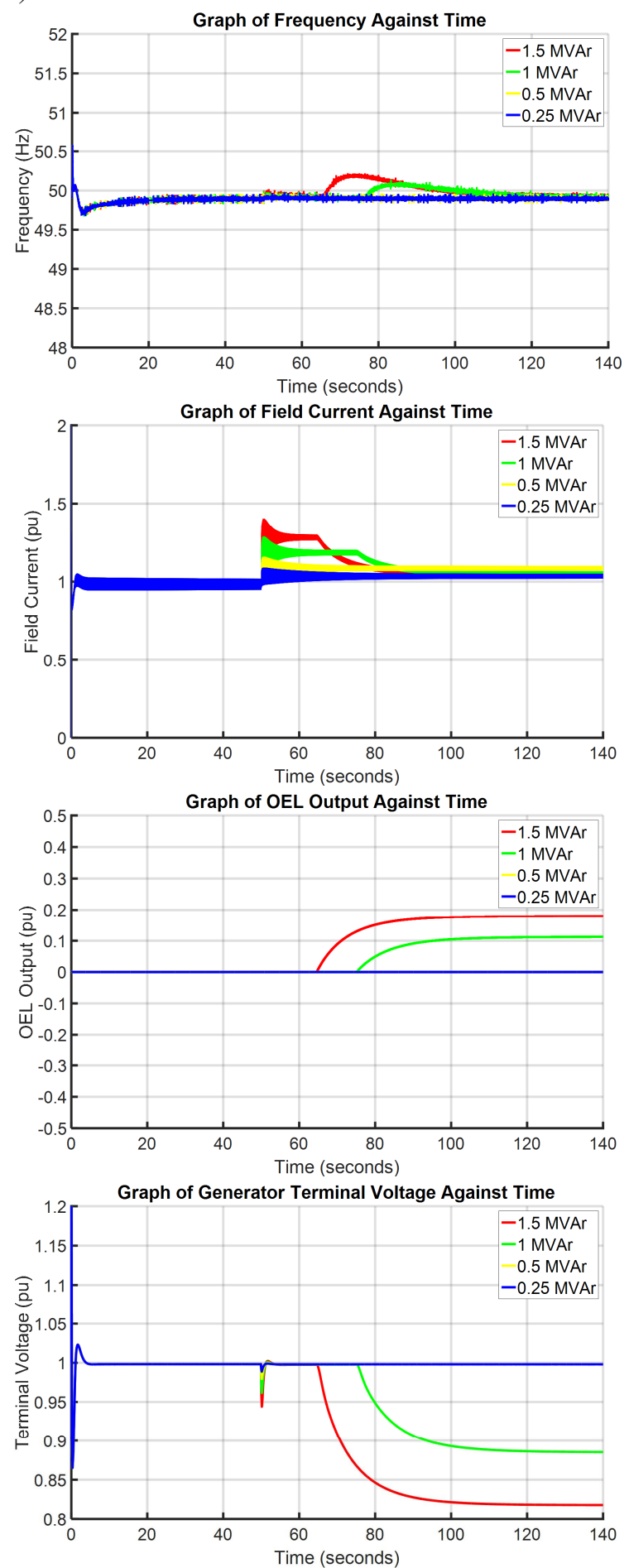

Figure 9. Response in grid-connected mode on different reactive load steps

\section{Supplementary Control}

As observed from the frequency response in island operation as shown in Fig. 7 and Fig. 9, the primary and secondary frequency control act as expected but there is no tertiary control available to return the frequency to its nominal value of $50 \mathrm{~Hz}$. A controller is thus proposed to generate a new reference speed to maintain the frequency at $50 \mathrm{~Hz}$. The determination of the controller parameters was through trial and error method. Fig. 10 shows the response on different $\mathrm{P}$ and I parameters.
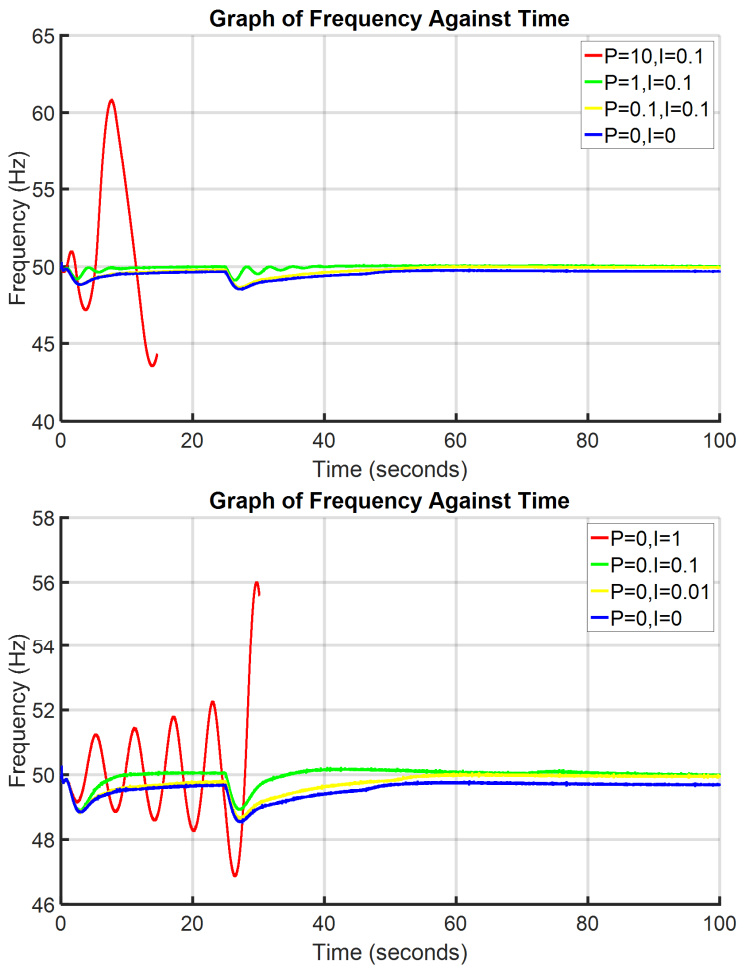

Figure 10. Effect of Tertiary Control Parameters

\section{DISCUSSION}

From Fig. 6 and Fig 7. the size of allowable step is different in both grid-connected and island mode. The maximum allowable active load step in island mode taking into account the minimum frequency of $49 \mathrm{~Hz}$ frequency is $200 \mathrm{KW}$. In grid-connected mode, the grid contributes in supplying the active power required thus minimum and faster frequency response is observed. The initial rise in OEL output as shown in Fig. 6 is due to SHPP initialization process. The subsequent rise in field current in active load steps is due to the fact that the turbine output increases to increase the speed thus retaining the frequency to normal. To match this, the flux strength is also increased thus increase in field current. The rise in field current is more pronounced in island mode than grid-connected mode as the grid is unavailable to assist in picking up the load. This issue led to a more pronounced drop in voltage (but still within limits) in island mode. In Fig. 8 and Fig. 9, the rise in reactive load influences the field current as expected and this triggers the OEL that in turn reduces the voltage. The rise in field current was more sensitive as compared to increase in active 
load steps due to the close coupling between reactive power and voltage that is controlled by the excitation system. The maximum allowable reactive load step, as can be determined by voltage minimum of $0.95 \mathrm{pu}$ is $300 \mathrm{KVAr}$. The increase in frequency is due to the dynamics associated with energization of pure inductive load. In reality, there is small resistance associated. In grid-connected mode, the maximum allowable load step is influenced by voltage stability. Finally, adding the PI controller at the governor in island mode aids in returning the frequency to its nominal value after operation of primary and secondary control. The proportional component of the controller increases the speed of response up to a certain point after which increasing oscillations can be observed. The integral part acts to reduce the steady-state error as desired and similar to the proportional component beyond a certain value the controller becomes unstable. The preferred choice of the Proportional and Integral component of the controller from the study becomes 1 and 0.1 respectively.

\section{CONCLUSION AND FUTURE DIRECTIONS}

Performance of SHPP, with the OEL and V/Hz limiters, in both grid-connected, and island mode has been investigated in this paper. Benchmark networks can now be used to investigate the influence of location of load on the SHPP performance. Effect of the UEL and capacitive loading should also be considered for future studies.

\section{ACKNOWLEDGEMENT}

The authors acknowledge funding support to carry out this research from Ministry of Business, Innovation and Employment, New Zealand's National Science ChallengeResilience to Nature's Challenge and in particular the project on Electricity Distribution Resilience Framework informed by West Coast Alpine Fault Scenario; University of Auckland under Faculty Research Development Fund (FRDF) Grant 3709532 and QuakeCoRE-New Zealand Centre for Earthquake Resilience.

\section{APPENDIX A - SYSTEM DATA}

\section{$\underline{\text { SHPP DATA }}$}

$\mathrm{S}=10 \quad$ MVA, $\mathrm{V}_{\mathrm{L}-\mathrm{L}}=11 \mathrm{KV}, \mathrm{H}=0.7 \mathrm{~s}, \mathrm{R}_{\mathrm{S}}=0.0029, \mathrm{X}_{\mathrm{d}}=2.06$, $\mathrm{X}_{\mathrm{d}}{ }^{\prime}=0.398, \mathrm{X}_{\mathrm{d}}{ }^{\prime}{ }^{\prime}=0.254, \mathrm{X}_{\mathrm{q}}=2.5, \mathrm{X}_{\mathrm{q}}{ }^{\prime}=0.254, \mathrm{X}_{\mathrm{L}}=0.1, \mathrm{~T}_{\mathrm{d} 0}=7.8$, $\mathrm{T}_{\mathrm{d} 0}, "=0.066, \mathrm{~T}_{\mathrm{q} 0},{ }^{\prime}=0.075$

\section{$\underline{\text { OEL DATA }}$}

$\mathrm{I}_{\mathrm{fd}, \mathrm{lim}}=1.05, \mathrm{~K}_{1}=1, \mathrm{~K}_{2}=0, \mathrm{~T}=10 \mathrm{sec}$

\section{$\underline{\mathrm{V} / \mathrm{HZ} \text { DATA }}$}

$\mathrm{V} / \mathrm{f}$, limit $=1.05, \mathrm{~K}_{1}=1000, \mathrm{~K}_{2}=0, \mathrm{~K}_{3}=1, \mathrm{~K}_{4}=0.007$

\section{REFERENCES}

[1] O. Paish, "Small hydro power: technology and current status," Renewable and Sustainable Energy Reviews, vol. 6, no. 6, pp. 537-556, 2002/12/01/ 2002 .
[2] D. K. Okot, "Review of small hydropower technology," Renewable and Sustainable Energy Reviews, vol. 26, pp. 515-520, 2013/10/01/ 2013.

[3] H. S. Sachdev, A. K. Akella, and N. Kumar, "Analysis and evaluation of small hydropower plants: A bibliographical survey," Renewable and Sustainable Energy Reviews, vol. 51, pp. 1013-1022, 2015/11/01/ 2015.

[4] P. J. Donalek, "Update on small hydro technologies, and distributed generation including run \&\#x2014; of \&\#x2014; river plants," in 2008 IEEE Power and Energy Society General Meeting - Conversion and Delivery of Electrical Energy in the 21st Century, 2008, pp. 1-2.

[5] A. Wijesinghe and L. L. Lai, "Small hydro power plant analysis and development," in 2011 4th International Conference on Electric Utility Deregulation and Restructuring and Power Technologies (DRPT), 2011, pp. 25-30-.

[6] H. Mohamad, H. Mokhlis, A. H. A. Bakar, and H. W. Ping, "A review on islanding operation and control for distribution network connected with small hydro power plant," Renewable and Sustainable Energy Reviews, vol. 15, no. 8, pp. 3952-3962, 2011/10/01/2011.

[7] P. S. Pravin and J. J. Abdul, "Performance evaluation of an isolated small hydro power plant using conventional controllers," in 2013 International Conference on Circuits, Power and Computing Technologies (ICCPCT), 2013, pp. 58-62.

[8] A. Dagoumas et al., "Transient analysis of distributed small hydro generators in a network," in 2005 International Conference on Future Power Systems, 2005, pp. 6 pp.-6.

[9] T. Toftevaag, T. Preda, and K. Uhlen, "Impact of voltage phase angle changes on low-voltage ride-through performance of small scale hydro DG units," in 22nd International Conference and Exhibition on Electricity Distribution (CIRED 2013), 2013, pp. 1-4.

[10] J. Peralta, H. Iosfin, and X. Tang, "BC Hydro perspective on distribution islanding for customer reliability improvement," in 2009 CIGRE/IEEE PES Joint Symposium Integration of Wide-Scale Renewable Resources Into the Power Delivery System, 2009, pp. 1-2.

[11] A. B. Piardi, J. R. Pesente, R. B. Otto, and R. A. Ramos, "Evaluation of Volts/Hertz and over-excitation limiters acting under unbalanced load conditions," in 2013 IEEE Power \& Energy Society General Meeting, 2013, pp. $1-5$

[12] P. Kundur, "Synchronous Machine Theory and Modelling," in Power System Stability and Control, N. J. Balu and M. G. Lauby, Eds.: McGraw-Hill, 1994.

[13] P. M. Anderson and A. A. Fouad, "The Synchronous Machine," in Power System Control and Stability, M. E. El-Hawary, Ed.: John Wiley \& Sons, 2003.

[14] P. W. Sauer and M. A. Pai, "Synchronous Machine Modelling," in Power System Dynamics and Stability, 1997.

[15] "Hydraulic turbine and turbine control models for system dynamic studies," IEEE Transactions on Power Systems, vol. 7, no. 1, pp. 167179, 1992.

[16] H. Gao and C. Wang, "Effect of Detailed Hydro Turbine Models on Power System Analysis," in 2006 IEEE PES Power Systems Conference and Exposition, 2006, pp. 1577-1581.

[17] C. Yin Chin, K. M. Muttaqi, and M. Negnevitsky, "Modelling of hydraulic turbine for dynamic studies and performance analysis," in 2007 Australasian Universities Power Engineering Conference, 2007, pp. 1-6.

[18] S. J. R. A. Naghizadeh, B. Vahidi, "Modeling Hydro Power Plants and Tuning Hydro Governors as an Educational Guideline," International Review on Modelling and Simulations, vol. 5, no. 4, pp. 1780-1790, 2012.

[19] M. J. Basler, "Excitation systems: the current state of the art," in 2006 IEEE Power Engineering Society General Meeting, 2006, p. 7 pp.

[20] "IEEE Recommended Practice for Excitation System Models for Power System Stability Studies," IEEE Std 421.5-2016 (Revision of IEEE Std 421.5-2005), pp. 1-207, 2016.

[21] C. D. Vournas, G. A. Manos, P. W. Sauer, and M. A. Pai, "Effect of overexcitation limiters on power system long-term modeling," IEEE Transactions on Energy Conversion, vol. 14, no. 4, pp. 1529-1536, 1999. 
[22] G. Anagnostou and B. C. Pal, "Impact of Overexcitation Limiters on the Power System Stability Margin Under Stressed Conditions," IEEE Transactions on Power Systems, vol. 31, no. 3, pp. 2327-2337, 2016.

[23] E. F. Alves and M. A. d. Souza, "Analysis of overexcitation relaying set up in synchronous generators for hydro power plants," in 2010 IEEE/PES Transmission and Distribution Conference and Exposition: Latin America (T\&D-LA), 2010, pp. 298-303.

[24] G. Benmouyal, "The Impact of Synchronous Generators Excitation Supply on Protection and Relays," presented at the 62nd Annual Georgia Tech Protective Relaying Conference, Georgia, 2008. 